\title{
DIAGNOOSI: HOMOSEXUALITAS 320.6
}

\section{Homoseksuaalisuuden tulkinnasta ja hoidosta Helsingin psykiatrian klinikalla 1954-1968}

\section{Katariina Parhi}

Tuoreehkossa kotimaisessa Tom of Finland -elokuvassa (2017) päähenkilö Touko Laaksosen ystävä joutuu poliisille kiinni jätyään psykiatriselle osastolle, tai näin ainakin annetaan ymmärtää. Laaksosen kanssa keskustelua käyvä hahmo näyttää murtuneelta, mutta hän on päättänyt parantua homoudestaan.

Elokuva alleviivaa tehokkaasti kahta historiallista tosiseikkaa: vuoteen 1971 saakka homoseksuaaliset teot oli kriminalisoitu, ja vuoteen 1981 saakka homoseksuaalisuus oli myös mukana kansainväliseen ICD-8-luokitukseen pohjautuvassa tautiluokituksessa (Tautiluokitus 1969, 40). Epäselväksi jää, oliko elokuvan potilas joutunut hoitoon pakotettuna, ja hoidettiinko häntä homoseksuaalisuutensa vuoksi. Vaikutelma on, että elokuvassa halutaan vahvistaa mielikuvaa seksuaalivähemmistöjen sulkemisesta mielisairaalaan. Lapinlahdessa sijainneen Helsingin yliopistollisen keskussairaalan psykiatrian klinikan arkistoaineisto ei tue tätä käsitystä.

Tämä puheenvuoro käsittelee Homosexualitas-diagnoosilla Lapinlahdessa hoidettuja potilaita ja mielentilatutkittavia vuosina 1954-1968, jolloin homoseksuaalisuus oli yksi psykopatiadiagnoosin alakategorioista tuolloin käytössä olleessa, aiempaan ICD-6-luokitukseen pohjautuvassa Tautinimistössä $(1953,40)$.Vuodet edustavat aikaa, jolloin suhtautuminen homoseksuaalisuuteen oli yhteiskunnassa tiukkaa: homoseksuaalisuus oli nostettu yleiseen tietoisuuteen, mutta se oli rikos. Rikoksen vuoksi ei kuitenkaan joutunut sairaalaan, ellei kyse ollut arvioidusta mielentilatutkimuksen tarpeesta.

Homosexualitas-diagnoosiin lukeutuivat tuolloin esimerkiksi tapaukset, joissa henkilö oli seksuaalisesti kiinnostunut oma sukupuolensa lapsista. Anakronismin välttämiseksi tarkastelen homoseksuaalisuutta tässä yhteydessä historiallisena käsitteenä. Tämä on merkittävää muun muassa siksi, että lapsia käytettiin kansainvälisestikin argumenttina dekriminalisoinnin vastustamisessa (ks. esim. George 2015, 225-261).

Aineisto koostuu kaikkiaan 19 potilaskertomuksesta ja edustaa kaikkia kyseisenä ajanjaksona hoidettavana olleita, homoseksuaaleiksi diagnosoituja potilaita, joiden potilaskertomus on ollut arkistosta löydettävissä. Käsittelen potilaskertomuksia ilman tarkkoja viitteitä akteihin, jotka olen kerännyt Helsingin yleisen sairaalan psykiatrian klinikan arkiston sairauskertomuksista vuosilta 1954-1968. Yksittäiset potilaat löytyvät tarvittaessa potilaspäiväkirjojen avulla Tautinimistön mukaisesti merkityllä 320.6 -koodilla, osana psykopatiaa. Aineisto liittyy laajempaan tutkimukseeni psykopatiadiagnoosin historiasta.
Katariina 


\section{Jahdatut homofiilit}

Sairaalaantulosyyt peilaavat vahvasti yhteiskunnallisia olosuhteita, joiden vuoksi oli raskasta olla homoseksuaalinen henkilö. Kaikkiaan 1026 miestä ja 51 naista tuomittiin vuosina 1894-1970. Tuomioiden määrää eri vuosina vertaillessa voi havaita, että asennoituminen oli tuomitsevinta heti toisen maailmansodan jälkeen. Huippuvuotta edusti vuosi 1951, jolloin langetettiin kaikkiaan 87 tuomiota (Mustola 2007, 221-222).

Toisen maailmansodan jälkeinen Suomi oli arvokonservatiivinen. Homoseksuaalisuutta Suomessa tutkineen Sandra Hagmanin mukaan miesten välisiä suhteita alettiin sotien aikana kutsua pysyvästi homoseksuaalisuudeksi, ja sota-aika myös teki homoseksuaalisuudesta ongelman (Hagman 2016, 162-163). Sota-aikana yleiset samansukupuoliset suhteet vaiettiin rauhan aikana kuoliaaksi niin Suomessa kuin muuallakin maailmassa (Juvonen 2002, 154; Herzog 2011, 98).

Salailu oli raskasta ja kiinnijäämisen pelko suuri. Eräs arkistoaineiston potilaista oli päätynyt ryyppäämään ja otti liikaa unilääkkeitä säikähdettyään reportteria, joka oli ollut kuvaamassa "homofilien" elämäntapoja. Osalla potilaista oli tuomio haureuden harjoittamisesta samaa sukupuolta olevan henkilön kanssa. Työyhteisössä oli ongelmia: potilasta haukuttiin homoksi ja hintiksi tai homoseksuaalisuus tuli muulla tapaa ilmi ja työpaikan menetys oli todellinen uhka.

Homoseksuaalisuusdiagnoosin vähäistä käyttöä psykiatrian klinikalla voi selittää se, että osa potilaista piti homoseksuaalisuutensa myös klinikalla visusti omana tietonaan. Diagnoosin saaneiden psyykkiset ongelmat olivat kietoutuneet heidän seksuaali-identiteettiinsä, mutta arkistoaineistosta käy ilmi, että hekään eivät välttämättä kertoneet psykiatrille kaikkea, mikä saattoi paljastua muita reittejä, tai sitten he kuvasivat muiden viettelyjä inhon vallassa, mikä ei ollut psykiatrien silmissä aina uskottavaa.
Kansainvälisessä vertailussa suomalainen keskustelu homoseksuaalisuudesta oli 1950-luvulla vähäistä ja siinä mielessä maltillista (Sorainen 1996, 189-190). Kiinnostus homoseksuaalisuutta kohtaan kuitenkin kasvoi, mahdollisesti osittain tarpeesta korostaa omaa "normaaliutta", ja se alkoi Ruotsista kantautuvista uutisista. Homouden katsottiin olevan rikollista, patologista ja vastenmielistä, ja se yhdistettiin enenevissä määrin pederastiaan eli aikuisen miehen ja nuoren pojan väliseen suhteeseen (Juvonen 2002, 86-87; Mustola 2007, 228-229).

Homoseksuaalisen henkilön kohtaamista pidettiin yleisesti vaarallisena, sillä ajateltiin, että homous voi tarttua (Hagman 2016, 178). Homoseksuaalisuus oli myös useamman aineiston potilaan mukaan jonkun opettamaa, mikä tukee heidän omaksumaansa käsitystä tai halukkuuttaan vahvistaa psykiatrien näkemystä. Homoseksuaalisuus manifestoitui nuoruuden kokemuksista tai taiteilijan, teatteri-ihmisen tai muun epäsovinnaiseksi tulkitun henkilön aktivoimana. Myös miesvaltaiset toimintaympäristöt, kuten vankila tai armeija, olivat potilaiden mukaan vaikuttaneet heidän homoseksuaalisuuteensa.

1950-luvun lopussa Jallu-lehti neuvoi homoseksuaaleja menemään psykiatrin tapaamiseen, sillä psykoterapia ja lääkitys johtivat jonkinlaisiin tuloksiin (Juvonen 2002, 95-96). Mikäli neuvoa on noudatettu, hoito on ollut luultavasti suurimmaksi osaksi polikliinista. Psykiatrian klinikan potilaiden oireina olivat voimakas syyllisyydentunto, ristiriitaisuuden tunne, ahdistus, pelko, häpeä, omantunnonvaivat ja kontaktivaikeudet. Kiinnijäämisen pelko saattoi olla niin voimakas, että se laukaisi "skitsofreniformisen paranoidisen psykoosin". Osa hyväksyi itsensä mutta oli kokenut ongelmia rakkauselämässä, osa lääkitsi ongelmiaan runsaalla ja holtittomalla alkoholinkäytöllä.

Potilaat, jotka olivat seksuaalisesti kiinnostuneita lapsista, kokivat olevansa piinattuja. Eräs oli vakuuttunut, että kaikki oli tapahtunut yhteisymmärryk- 
sessä, mutta hän oli alkanut epäröidä: "Olen tajunnut sen, että oikein se ei varmasti ole, koska olen kärsinyt siitä itse niin paljon. Olen rukoillutkin, että pääsisin irti siitä. Se on tuottanut helvetin tuskia monta kertaa. Ei ole helppoa elää kaksoiselämää. - - Olen vaiennut ja kärsinyt oman sairauteni.”

Vaikka homoseksuaalisuudesta jaettiin tuomioita, on mielentilatutkimusten joukossa vain vähän Homosexualitas-diagnoosia. Niiden taustalla olevat rikokset liittyivät yleisimmin haureuden harjoittamiseen alaikäisten henkilöiden kanssa. Ennen vuotta 1926 rikoslaki ei ollut edes tunnistanut poikia seksuaalisen hyväksikäytön uhreiksi, sillä heidät nähtiin rikoskumppaneina, ja kyse oli tällöin samaa sukupuolta olevien välisestä haureudesta (Hagman 2016, 41-42).

Mielentilalausunnot vastaavat loppuponsiltaan muita psykopatiadiagnoosin saaneiden tutkittavien lausuntoja. Niissä oli varsin tavallista todeta tutkittavan, niin kuin mielentilatutkimuksissa olevia nimitettiin, olleen täyttä ymmärrystä vailla. Se puolestaan viittasi alentuneeseen syyntakeisuuteen (Parhi ja Lauerma 2016, 2089-2097). Psykiatrien mukaan seksuaalinen poikkeavuus oli niin vahva ja seksuaalitoiminta niin määräilevä eli dominoiva, ettei tutkittava ollut kyennyt harkitsemaan haureustekojensa tarkoitusta eikä seurauksia. Yhdellä tutkittavalla diagnosoitiin myös lievää älyllistä kehitysvammaisuutta, jonka vuoksi todettiin, ettei hänellä ollut edellytyksiä ymmärtää oman sielunelämänsä laatua ja poikkeavuutta.

Erään tutkittavan katsottiin syyllistyneen murhaan ja murhayritykseen, joissa seksuaalinen kiihtymys näytteli osaa. Häntä kuvattiin seuraavanlaisesti: "Seksuaalinen kehitys ollut haparoiva, suhteessa naisiin alemmuudentuntoinen. Alemmuuden- ja depressiontunteet sangen vahvat, jotka estäneet saavuttamasta normaaleja sukupuolenkohteita. Saaneet destruktiotaipumuksia, joihin liittyy aggressiot.” Tutkittava oli psykiatrin tulkinnan mukaan ollut tekojen aikaan viettimäisten impulssien vallassa.
Koska väkivalta ei olisi ollut seksuaaliseen tyydytykseen välttämätön, arveltiin, että aggression merkitys oli suurempi. Alentuneeseen syyntakeisuuteen liitettiin toisinaan näkemys poikkeavista vieteistä. Psykiatrien tulkinnoissa seksuaalinen poikkeavuus oli vahvempi kuin "normaali" sukuvietti ja vaati tyydystä

\section{Psykiatrien tulkinnat ja hoito}

Viittaus seksuaalisen kehityksen haparoivuuteen ja kiinnostus miestutkittavan naissuhteisiin peilaavat laajemmin aikakauden psykiatrian näkemyksiä. Vuonna 1971 julkaistussa Psykiatria-oppikirjassa tiivistettiin hoitokokemuksia seuraavasti: "Monesti hoidon edellytyksiä ja tuloksia rajoittaa asianomaisen riittämätön motivaatio muuttumiseen. Tuottavathan homoseksuaaliset suhteet hänelle seksuaalista tyydytystä, ja toisaalta ilmenee, että heteroseksuaalisen kehityksen estymiseen vaikuttavat tekijät ovat ahdistavia." (Achté, Alanen ja Tienari 1971, 652.) Parantuminen homoseksuaalisuudesta olisi käsityksen mukaan mahdollista, ellei henkilö itse vastustaisi sitä niin ponnekkaasti.

Psykiatrit tulkitsivat aineiston perusteella homoseksuaalisuutta psykoanalyyttisessä viitekehyksessä: Homoseksuaalisuus saattoi liittyä äitisuhteeseen, joka oli useamman tapauksessa ollut huono. Potilas oli saattanut myös identifioitua isäänsä, jonka vuoksi tunsi naisena kiinnostusta naisia kohtaan. Epäonninen rakkaussuhde naiseen oli saanut erään potilaan hakemaan naista pojista, joiden ruumiillinen hahmo muistutti potilasta rakkautensa kohteesta. Psykiatrisen tulkinnan mukaan potilaalla oli syntynyt "voimakas esto toiseen sukupuoleen". Yhdessä tapauksessa potilas ei ikänsä vuoksi kyennyt enää kilpailemaan tavanomaisista kiinnostuksenkohteista vaan joutui siksi suuntaamaan kiinnostuksensa tavallisen kilpailun ulkopuolella oleviin kohteisiin - poikalapsiin.
Pervo/ peruutus/peili Keskustelua

西

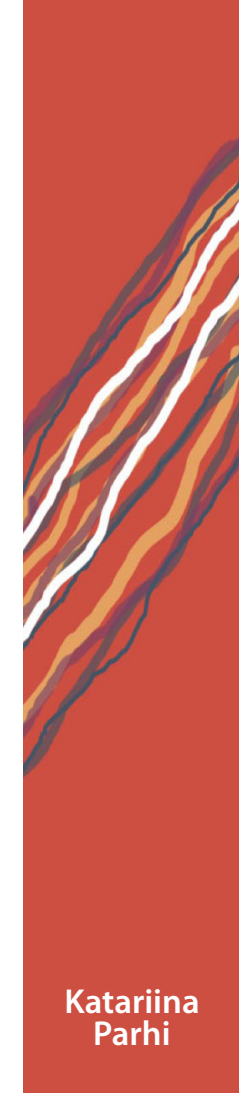


Psykiatrien potilaita koskevissa muistiinpanoissa on tehty ero manifestin ja ei-manifestin homoseksuaalisuuden välille. Homoseksuaalisuus oli osittain taipumus, jonka voisi halutessaan painaa pinnan alle. Potilasta saatettiin kuvata toteamalla, ettei tämä ollut päättänyt, toteuttaako homoseksuaalisuutensa jatkamista. Psykiatrit kuvasivat potilaiden kehittymistä homoseksuaaleiksi niin, että seksuaalisuus oli kuin piilossa oleva voima, joka aktivoitui ärsykkeistä.Jo vuonna 1919 psykiatri Akseli Nikula (1919, 258) kuvasi homoseksuaalisuuden oikeudellista arvostelua koskevassa artikkelissaan homoseksuaalisuuden syitä ja mainitsi riskeinä onanian, juopuneisuuden, viettelyksen, kansantapojen ja samassa sängyssä nukkumisen tai yhdessä kylpemisen.

Homoseksuaalisuus saattoi psykiatrien tulkintojen mukaan kehittyä ulkoisten syiden seurauksena. Eräs potilas "joutui homosexuaalisuuden pauloihin", koska ei ollut saanut äidiltään tukea, turvaa ja hellyyttä, ja koska hänen aikaisempi heteroseksuaalinen suhteensa oli päättynyt pettymykseen.

Brittiläisiä homoseksuaalisuuden hoitomuotoja 1950-luvulta alkaen kartoittaneessa tutkimuksessa kuvataan suoraan seksuaalisuuteen kohdistettuja keinoja, kuten libidoa vähentävää estrogeenia, sähköshokein ja apomorfiiniannoksin ryyditettyä aversioterapiaa ja parantumiseen tähtäävää psykoanalyysia (Smith, Bartlett ja King 2004). Aineistostani ei löydy tämänkaltaisia systemaattisia "parannusyrityksiä". Tärkein hoitomuoto homoseksuaalisuusdiagnoosin saaneille potilaille oli supportiivinen psykoterapia: Kuten Psykiatria-oppikirjassakin todettiin, ymmärtävän henkilön tuki oli hyvin tärkeää. Supportiivisella psykoterapialla oli tarkoitus lievittää ahdistuneisuutta, syyllisyydentunteita ja ihmissuhderistiriitoja (Achté, Alanen ja Tienari 1971, 652). Käytännössä ymmärtävää tukea on hankala määritellä, mikäli psykiatrin perimmäinen uskomus oli, että homoseksuaalisuudesta voisi riittävällä yrittämisellä parantua.
Potilaskertomuksiin tallentuneesta tiedosta on mahdotonta selvittää varmuudella, kokivatko potilaat saavansa klinikalla helpotusta. Homoseksuaalisuuden parantamisyrityksiä ei löydy potilaskertomuksista. Polikliinisessa hoidossa on toki voinut olla henkilöitä, jotka ovat itse halunneet parantua, ja tällöin psykiatrin teoreettinen näkemys homoseksuaalisuudesta parannettavana sairautena on voinut ohjata hoitoa voimakkaammin. Eräällä potilaalla todetaan supportiivisen psykoterapian (vain) hetkellinen vaikutus.

Joitakin merkkejä supportiivisesta psykoterapiasta ja potilaan tilanteen ymmärryspyrkimyksestä on potilaskertomuksiin tallentunut, kuten seuraava maininta potilaan suhteesta: "Keskusteluissa hyväksytään tuo suhde, mutta vain se, ei uusien ensikertalaisten taivuttamista homoseksualismiin. Potilaalle tehdään ymmärrettäväksi hänen abnormaliteettinsä suuntautuminen tähän suuntaan hänen elämänkaarensa perusteella. Lähtee pois sairaalasta helpottuneena." Muistiinpanosta käy ilmi sekä käsitys homoseksuaalisuuden tarttuvuudesta että psykoanalyyttisen teorian merkitys terapiassa: elämänkaareen viittaus merkitsee potilaan huonoa äitisuhdetta.

Vaikuttaa siltä, että jo olemassa oleviin suhteisiin suhtauduttiin hyväksyvästi, mutta homoseksuaalisuuden toteuttaminen oli rikos, joten psykiatrikunnan tehtävänä oli suojella potilaita lain rikkomiselta: "Interpretoidaan asioita enemmän hyväksyvään henkeen. Tämä suhde hyväksytään, mutta selitetään vaarat joita voi seurata, jos houkuttelee aikaisemmin tässä suhteessa 'viattoman' h-s:ään mukaan. Puhutaan lain kiellosta ja todetaan juridiikan tässäkin epäedukseen poikkeavan medisiinasta." Muistiinpanon kirjoittanut psykiatri vaikuttaa vastustaneen kriminalisointia, mutta on muistettava, että näkemyksiä on ollut yhtä monta kuin psykiatrejakin.

Potilailla kuvattiin psykiatrisia oireita homoseksuaalisuusdiagnoosin lisäksi sekä ensimmäisenä että toisena diagnoosina. Niiden hoito on voinut auttaa yleisvointiin, vaikka Olli Stålström onkin kritisoinut tuolloista homoseksuaalisuuden ongelmien patologisointia (Stålström 1998, 303).

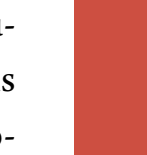


Käytännössä lienee mahdotonta erotella, minkä on katsottu johtuvan mistäkin. Kun kyseessä oli "maniko-depressiivinen reaktio", sitä hoidettiin aineistomerkintöjen mukaan insuliinihoidolla. Alkoholismia hoidettiin erilaisilla lääkkeillä, esimerkiksi Largactililla, joka oli uusi psyykenlääke. Potilaan taustalla saattoi olla myös itsemurhayritys tai sen simulointi, masennuskausia ja "depersonalisaatioelämyksiä".

Kaksi potilasta sai merkintöjen mukaan hormonipistoksia, mutta niistä ei ollut todistettavaa apua. Arkistoaineiston perusteella ei voi sanoa, onko hormoneja annettu Suomessa systemaattisemmin. Viimeistään 1970-luvulle tultaessa hormonihoidot katsottiin tehottomiksi (Achté, Alanen ja Tienari 1971, 652). Hormonipistosten antamiseen liittyi oletus siitä, että homoseksuaalisuuden perustana oli sukupuolihormonien epätasapaino. Ensimmäiset kokeilut tehtiin Yhdysvalloissa vuonna 1940. Tunnetuin tapaus lienee brittiläinen matemaatikko Alan Turing, jonka kemikaalihoidon on katsottu vaikuttaneen hänen itsemurhaansa vuonna 1954 (Vitelli 2014, 143-146). On mahdollista, etteivät hormonihoidot ole kaikilta osin tallentuneet, sillä anabolisia steroideja käytettiin erilaisiin vaivoihin, ja niillä on voitu tehdä kokeiluja kaikessa hiljaisuudessa.

\section{Lopuksi}

Arkistoaineistot eivät tue käsitystä sairaalahoidosta osana ajanjakson homojen yleisempää kohtelua. Ainakin sairaalaan sulkeminen, ja oikeastaan myös sairaalahoito, oli lähes olematonta ja sitoutui potilaiden muihin vaikeuksiin. Polikliinisen hoidon tutkimus voisi avata lisänäkökulmia. Myös vuodet 1971-1981 olisivat hedelmällinen ajanjakso tutkittavaksi, sillä homoseksuaalisten tekojen dekriminalisointi vähensi asteittain salailun tarvetta. Homoseksuaalisuus muuttui näkyvämmäksi, ja aktivistit ajoivat seksuaalivähemmistöjen oikeuksia. Samaan aikaan sairausstatus säilyi vielä vuosikymmenen, eivätkä ajatukset homoseksuaalisuudesta patologiana kadonneet senkään jälkeen. Yhdysvaltalaispsykoanalyytikoiden piirissä asennemuutos oli 1980-luvun alusta lähtien asteittainen (ks. Friedman ja Lilling 1997, 79-89), ja katsaus suomalaisten psykoanalyytikoiden kirjoituksiin tuolta ajalta antaa samankaltaisen kuvan.

Vielä ICD-10 eli nykyään käytössä oleva tautiluokitus luettelee diagnoosin F66 alla niin sukupuoliseen kypsymiseen kuin itseä häiritsevään sukupuoliseen suuntautumiseen liittyviä alakategorioita (ICD-10, 254-255). Tulossa olevaan ICD-11:een on ehdotettu laajalti muutoksia liittyen häiriön käsitteen tulkitsemisen ristiriitoihin (ks. Reed et al. 2016, 205-221).

Stålströmin $(1998,310)$ mukaan psykoanalyytikot hidastivat homoseksuaalisuuden sairausleiman poistumista. Kokisin merkitykselliseksi selvittää tarkemmin, missä määrin psykoanalyyttiseen ajatteluun liittynyt usko parantumisen mahdollisuuteen vaikutti asenneilmapiiriin. Muun tutkimuksen ohessa tekemäni havainnot Oulun keskusmielisairaalan aineistosta antavat erilaisen kuvan homoseksuaalisuuskäsityksistä. Sairaalan toimintaa leimasi laajalti pyrkimys keskittyä "oikeisiin" mielisairauksiin (ks. Parhi ja Pietikäinen 2017, 637-660). Psykoanalyyttisen psykiatrian sijaan siellä oli vahva biologinen painotus, jonka mukaan ihmiset syntyivät, eivät kehittyneet, tietynlaisiksi. "Muuttumiseen" tai "parantumiseen" ei uskottu. Tämä ei tietenkään poissulje sitä, että potilaskertomusten tavoittamattomissa saattoi olla oma asennemaailmansa.

Helsingin psykiatrian klinikan arkistoaineisto valottaa pientä mutta merkittävää osaa homoseksuaalisuuden tulkinnoista Suomessa toisen maailmansodan jälkeen. Potilaat kärsivät selvästi homoseksuaalisuuden tuomitsevassa yhteiskunnassa. Psykiatrit pyrkivät helpottamaan potilaiden oloa ja rohkaisivat hyväksyvään suhtautumiseen, mutta pitivät samanaikaisesti homoseksuaalisuutta sairautena, josta voisi halutessaan parantua.

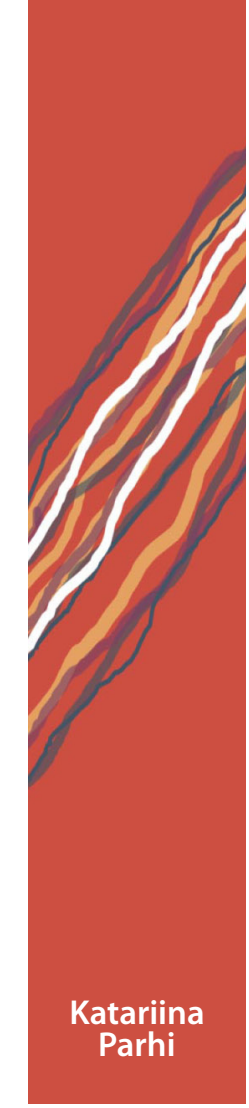




\section{Kirjallisuus}

Achté Kalle, Yrjö Alanen ja Pekka Tienari. 1971. Psykiatria. Porvoo: Werner Söderström Osakeyhtiö.

Friedman, Richard C. ja Arthur A. Lilling. 1997. "An Empirical Study of the Beliefs of Psychoanalysts About Scientific and Clinical Dimensions of Male Homosexuality". Journal of Homosexuality 32(2): 79-89.

George, Marie-Amelie. 2015. "The Harmless Psychopath: Legal Debates Promoting the Decriminalization of Sodomy in the United States". Journal of the History of Sexuality 24(2): 225-261. https://doi.org/10.7560/ JHS24203

Hagman, Sandra. 2016. Seitsemän kummaa veljestä: Kertomuksia suomalaisen homoseksuaalisuuden historiasta. Tallinn: Gaudeamus Helsinki University Press.

Herzog, Dagmar. 2011. Sexuality in Europe: A Twentieth-Century History. New York: Cambridge University Press. https://doi.org/10.1017/ CBO9780511997075

Juvonen, Tuula. 2002. Varjoelämää ja julkisia salaisuuksia. Jyväskylä: Vastapaino.

Mustola, Kati. 2007. "Finland 1889-1999. A Turbulent Past". Teoksessa Criminally Queer. Homosexuality and Criminal Law in Scandinavia 1842-1999, toimittaneet Jens Rydström ja Kati Mustola. 215-250. Amsterdam: Aksant.

Nikula, Akseli. 1919. "Homoseksualiteetti ja sen forenssinen arvosteleminen." Duodecim 7-8: 248-273.

Parhi, Katariina ja Hannu Lauerma. 2016. ”Psykopatiakäsitteen muuttunut rooli oikeuspsykiatriassa: Syyntakeisuutta vähentävästä häiriöstä tuomion koventamisperusteeksi”. Duodecim 132: 2089-2097.

Parhi, Katariina ja Petteri Pietikäinen. 2017. "Socialising the Anti-Social: Psychopathy, Psychiatry and Social Engineering in Finland, 1945-1968". Social History of Medicine 30(3): 637-660.

Reed, Geoffrey, Jack Drescher, Richard B. Krueger, Elham Atalla, Susan D. Cochran, Michael B. First, Peggy T. Cohen-Kettenis, Iván Arrango-de Montis, Sharon J. Parish, Sara Cottler, Peer Briken, and Shekhar Saxena. 2016. "Disorders related to sexuality and gender identity in the ICD-11: revising the ICD-10 classification based on current scientific evidence, best clinical practices, and human rights considerations". World Psychiatry 15(3): 205-221. https://doi.org/10.1002/wps.20354
Smith, Glenn, Annie Bartlett ja Michael King. 2004.'Treatments of Homosexuality in Britain since the 1950s - an Oral History: The Experience of Patients". BMJ 328: 427. https://doi.org/10.1002/wps.20354

Sorainen, Antu. 1996. "Rikollisia sattumalta. Oikeustapauksia naisten keskinäisestä haureudesta 1950-luvun Itä-Suomesta". Teoksessa Matkoja moderniin: Lähikuvia suomalaisten elämästä, toimittanut Marjatta Rahikainen, 187-212. Helsinki: Suomen Historiallinen Seura.

Stålström, Olli. 1998. Homoseksuaalisuuden sairausleiman loppu. Helsinki: Gaudeamus.

Tautiluokitus. 1969. Helsinki: Valtion painatuskeskus.

Tautiluokitus ICD-10. 1999. 2. painos. Turenki: Sosiaali- ja terveysalan tutkimusja kehittämiskeskus.

Tautinimistö: Nomenclatura statistica internationalis morborum et traumatum et causarum mortis. 1953. Helsinki: Valtioneuvoston kirjapaino.

Tom of Finland (2017). O: Dome Karukoski. T: Helsinki Filmi Oy, Anagram, Fridthjof Film, Neutrinos Productions, Film i Väst. Suomi, 116 min.

Vitelli, Romeo. 2014. "Anabolic Steroids in the Treatment of Homosexuality". Teoksessa Steroids and Doping in Sports: A Reference Handbook, toimittanut David E. Newton, 143-146. California: ABC-CLIO.
SQS

$1-2 / 2018$

Pervo/ peruutus/peili Keskustelua 